\title{
O SENTIMENTO DO FALANTE NOS MANUSCRITOS SAUSSURIANOS
}

\author{
THE SPEAKER'S FEELING IN SAUSSURE'S MANUSCRIPTS
}

\author{
Aline Vargas Stawinski ${ }^{1}$ \\ Luiza Ely Milano ${ }^{2}$
}

\begin{abstract}
RESUMO: Este artigo tem como objetivo abordar o conceito de falante a partir dos estudos de Ferdinand de Saussure, relacionando-o ao termo sentimento presente nas fontes manuscritas. Há duas formas pelas quais o sentimento é tomado na leitura saussuriana: como sentimento do falante e como sentimento da langue. Lançamos mão do léxico de Rudolf Engler (1968) e do levantamento terminológico realizado por Giuseppe Cosenza (2016) a fim de analisar as implicações do termo para a reflexão linguística saussuriana. A ambiguidade entre sentimento do falante e sentimento da langue, promovida pela própria leitura das fontes, ampara a aproximação teórica entre falante e langue - conceitos fundamentais à reflexão teórica de base saussuriana. Vemos a noção de sentimento, assim, como um princípio epistemológico capaz de fundamentar a problemática da delimitação das unidades linguísticas na cadeia discursiva, promovendo a indissociabilidade entre langue e parole.
\end{abstract}

PALAVRAS-CHAVE: Falante. Langue. Parole. Sentimento.

ABSTRACT: This article aims to address the concept of speaking subject (sujet parlant) in relation to the term feeling (sentiment), both present in Saussure's manuscript sources. The reading of Saussure's notes allows the interpretation of the term feeling in two ways: the feeling of the speaking subjects and the feeling of the language (langue). This study considers the lexicon of Rudolf Engler (1968) and the terminological collection of Giuseppe Cosenza (2016) in order to analyze the implications of the term for Saussurean linguistic thought. The ambiguity between the feeling of the speaking subjects and the feeling of the language (langue) promoted by the reading of the manuscripts supports the theoretical approach between speaking subject and language (langue) - both essential concepts in Saussure's theoretical framework. Thus, the term feeling seems to operate as an epistemological principle. Such a notion underlies the problem of distinguishing linguistic units in speech, which reinforces the intrinsic relationship between langue and parole.

KEYWORDS: Feeling. Langue. Parole. Speaking subject.

\section{Considerações iniciais}

Ferdinand de Saussure é conhecido fundamentalmente por sua obra póstuma, o Curso de Linguística Geral (1974 [1916]) ${ }^{3}$. Apesar de ter publicado pouco - segundo Estanislao Sofia (2019), apenas 10\% do conjunto de escritos deixados por Saussure foi publicado em vida -, Saussure deixou um vasto material de manuscritos, os quais testemunham a pesquisa constante do professor e linguista suíço em busca da definição e delimitação de seu objeto de estudos - a langue ${ }^{4}$. O estudo de parte desse amplo acervo de notas manuscritas permitiu-nos vislumbrar como a problemática do método se faz presente nas considerações saussurianas -, e a questão

\footnotetext{
${ }^{1}$ Doutora em Estudos da Linguagem pela Universidade Federal do Rio Grande do Sul (UFRGS).

2 Professora do Departamento de Letras Clássicas e Vernáculas da Universidade Federal do Rio Grande do Sul (UFRGS) e professora e orientadora no Programa de Pós-graduação em Letras na mesma universidade.

${ }^{3}$ Livro editado e organizado pelos colegas Charles Bally e Albert Sechehaye, com contribuição de Albert Riedlinger, a partir de anotações de alunos dos três cursos ministrados por Saussure na Universidade de Genebra, entre os anos de 1907 e 1911. Nesse trabalho, alternaremos o uso do título completo do clássico livro de Saussure, Curso de Linguística Geral, e a já conhecida sigla CLG.

${ }^{4}$ Neste trabalho, seguiremos a sugestão de Ribeiro (2019) ao utilizar os termos langue e parole em francês, tal como nos documentos saussurianos, para evitar a confusão com a ideia de idioma e de realização articulatória, respectivamente, que a tradução para o português possa vir a evocar. Manteremos os termos em português quando não se tratar dos conceitos, ou seja, quando forem utilizados como substantivo comum.
} 
do "sentimento do falante" sobre a qual nos debruçaremos a seguir parece tratar-se, justamente, de um problema metodológico.

Um olhar direcionado ao objeto e método da linguística sincrônica proposta por Saussure foi já sugerido em Stawinski e Milano (2017) - a questão do aspecto fônico da língua a partir do Curso e do manuscrito Phonétique (SAUSSURE, 1995) possibilitou encarar a complexidade do fenômeno linguístico levando em consideração, particularmente, os aspectos concreto e abstrato para a delimitação das unidades linguísticas na cadeia falada (chaîne parlée). Tal perspectiva teve como objetivo sublinhar o problema semiológico do signo ${ }^{5}$, assim como o lugar da percepção das unidades pelo falante-ouvinte de uma língua.

Avançando na questão da percepção - ou do recorte das unidades linguísticas, para utilizar uma expressão saussuriana -, em Milano e Stawinski (2020), interrogamo-nos acerca do conceito de arbitrário e sua relação com a noção de escuta. A escuta, apesar de não ser efetivamente um termo utilizado por Saussure, parece estar implícita em diversas reflexões do linguista, particularmente naquelas relacionadas ao aspecto fônico da língua, assim como às discussões sobre o que podemos definir como langue. Já a expressão "sentimento" e a presença do falante no pensamento saussuriano não são novidade. Alessandro Chidichimo (2009), Loïc Depecker (2012) e Emanuele Fadda (2013) apontaram a presença do termo e sua ambiguidade com relação ao falante ou ao conceito de langue. Entretanto, resta ainda explorar a importância de tal reflexão e ampliá-la, assim como verificar suas implicações para a definição de falante sob um viés linguístico. Nesse sentido, acompanhando as discussões de Castro (2018) e de Silva $(2018)^{6}$, buscamos trazer mais elementos para o diálogo integrativo dos conceitos langue e parole a partir da noção de sentimento (sentimento da langue, sentimento do falante).

No presente artigo, portanto, buscamos refletir acerca do falante e da langue a partir da noção de sentimento. Para isso, lançaremos mão do Léxique de la térmilologie saussurienne de Rudolf Engler (1968) ${ }^{7}$ e da obra de Giuseppe Cosenza (2016), intitulada Dalle parole ai termini - I percorsi di pensiero di F. de Saussure, na qual o pesquisador realiza um estudo detalhado das terminologias (no plural) pensadas a partir da diversidade que compõe o corpus saussuriano. A pesquisa de Cosenza será aliada à leitura de estudiosos contemporâneos cujas discussões dedicam-se precisamente à problemática do sentimento e suas implicações no pensamento elaborado por Ferdinand de Saussure.

Antes de aprofundarmos a discussão e avançarmos em nossa questão específica, cabe contextualizarmos o trabalho empreendido por Cosenza (2016). O livro, prefaciado pelos experientes linguistas italianos Daniele Gambarara e Emanuele Fadda, tem como objetivo refletir acerca da questão terminológica no contexto dos textos saussurianos (os documentos autográficos), empreitada complexa, mas necessária, em decorrência da diversidade da natureza dos manuscritos de Saussure, seja com relação ao gênero mesmo, seja com relação à temática tratada em cada escrito ou à época em que seus textos foram produzidos. Não à toa, fala-se da flutuação terminológica perceptível no Curso de Linguística Geral (SAUSSURE, 1974 [1916]) - resultado não somente da interpretação dos editores, mas da mudança inerente a um pensamento em desenvolvimento. É justamente a característica de um pensamento em construção que Giuseppe Cosenza acaba generosamente fornecendo aos leitores da sua coleção

\footnotetext{
${ }^{5}$ Nesse sentido, dá-se mais um passo na discussão sobre o estatuto do fônico do signo linguístico, em seu viés simultaneamente concreto e abstrato, amparando assim a reflexão sobre objeto e método no projeto semiológico de Ferdinand de Saussure (MILANO, 2017).

${ }^{6}$ Ambos os trabalhos têm como ponto de partida a discussão da analogia em Saussure. Enquanto o estudo de Castro parte da "consciência da língua" como suporte para a investigação do fenômeno analógico (CASTRO, 2018, p. 832), a reflexão de Silva contribui para o questionamento acerca das noções de "psicológico" e "psíquico", ao se perguntar sobre a natureza do sentimento do falante nas construções analógicas (SILVA, 2018, p. 932).

${ }^{7}$ Doravante Léxique ou LTS (Engler, 1968).
} 
terminológica: o pesquisador divide a coleção em quatorze grupos de fontes manuscritas ${ }^{8}$; cada grupo conta com sua própria coleção de termos, definidos por Cosenza com apoio irrestrito nos manuscritos, cujos trechos são transcritos a fim de exemplificar cada concepção - conforme veremos em detalhe ao nos debruçarmos sobre as entradas terminológicas.

É a partir dessas obras dedicadas ao léxico e às terminologias saussurianas que buscaremos olhar para o termo sentimento tendo como horizonte a compreensão do falante e de sua relação indissociável com a langue. Os desdobramentos teóricos possíveis a partir do estudo dos termos, assim como dos estudos de releitores da obra saussuriana, mostram-nos que há caminhos de abertura para a interpretação dessas noções. Propomo-nos, portanto, a abordar os conceitos de falante a partir de Ferdinand de Saussure desde uma perspectiva epistemológica, relacionando o termo à noção de sentimento linguístico presente nas fontes manuscritas selecionadas de acordo com as indicações de Cosenza (2016), conforme veremos a seguir.

\section{O falante a partir de Saussure}

Afinal, podemos sustentar que Saussure levou em conta o falante nas suas considerações linguísticas? O leitor não especializado no conjunto de fontes que forma aquilo que hoje denominamos o corpus saussuriano pode ser levado ainda a pensar que não, afinal, a langue, caracterizada como um sistema de valores relativos, opositivos e negativos é enfatizada como (único) objeto da linguística. A oposição exposta no CLG entre linguística da langue e linguística da parole (cf. SAUSSURE, 1974 [1916], p.26) pode reforçar tal compreensão, levando a crer que o falante, em última instância, faria parte de uma linguística da parole excluído, portanto, da linguística da langue. Reelaboramos, assim, a pergunta: afinal, o que se entende por falante na reflexão saussuriana, e como este conceito está relacionado com os conceitos de langue e parole? Para que possamos refletir sobre essas considerações, lançamos mão das entradas terminológicas referentes a sujet parlant ${ }^{9}$ presentes no levantamento de Giuseppe Cosenza (2016). Adiante, em Depecker (2012), estabelecemos uma aproximação entre os termos "consciência" e "sentimento".

A coleção terminológica de Cosenza (2016) mostra-nos, no manuscrito Phonétique (1881-1884), que ofalante é identificado como a pessoa que fala:

Sujet parlant: [hapax. a pagina 109 nota 390 , il termine è stato sostituito con la personne qui parle]; Il n'y a jamais de nécessité matérielle que dans les limites où celle nécessité découle de cette subordination arbitraire du sujet parlant, ou du phonétiste lorsqu'il réduit le problème concret qui se pose à un problème abstrait. (p. 172) Cfr. langue, parole $\{E D ;$ Notes Item; LG; I corso; II corso; III corso $\}$. (COSENZA, 2016, p.307)

Em De la double essence du langage (1891-1892), o falante, novamente, é caracterizado pela pessoa que fala uma língua - sendo que esta definição associa o falante à consciência de um estado de língua:

Sujet parlant: [individuo che parla una lingua, la cui coscienza linguistica costituisce il punto di riferimento per lo studio degli stati di lingua (Cfr. conscience, état de langue)]; La première expression de la réalité serait de

\footnotetext{
${ }^{8}$ A coleção terminológica elaborada por Giuseppe Cosenza é organizada em grupos, os quais dividem-se entre as seguintes fontes manuscritas: Ensaios da juventude (1874), Mémoire (1878), Tese sobre o genitivo em sânscrito (1881), Phonétique (1881-1884), Produções genebrinas (1891), De la double essence du langage (1891-1892), Satus et Motus (1893-1894), Notes Whitney (1894), Théorie des sonantes (1895-1897), Notes Item (1899-1903), Lendas germânicas (1903-1910), Primeiro Curso de Linguística Geral (1907), Segundo Curso (1908-1909), Terceiro Curso (1910-1911).

${ }^{9}$ Optamos por utilizar o termo falante para nos referirmos a sujet parlant.
} 
dire que la langue (c'est-à-dire le sujet parlant) n'aperçoit ni l'idée $a$, ni la forme $\mathrm{A}$, mais seulement le rapport $a / A$; cette expression serait encore tout à fait grossière. Il n'aperçoit vraiment que le rapport entre les deux rapports $a / A H Z$ et $a b c / A$, ou $b / A R S$ et $b l r / B$ etc. (p. $156 \S 79$ ); Cfr. conscience, esprit, état de langue, langue, mental, modification, opération, opposition, pensée, psychique, sentiment. $\{\mathrm{Ph}$; Notes Item; LG; I corso; II corso; III corso $\}$. (COSENZA, 2016, p.360)

Como lemos acima, langue chega a ser definida como uma espécie de sinônimo de falante - "a langue (ou seja, o falante)" - visto que é precisamente a posição de falante (e ouvinte) de determinada língua o que permite delimitar, na cadeia discursiva, o que é (ou não) langue, o que pertence (ou não) à determinada língua. A noção de que o falante só tem consciência do signo a partir da relação indissociável entre forma e sentido também está presente em outros manuscritos ${ }^{10}$.

Na entrada referente ao Primeiro Curso (1907), Cosenza sintetiza bem as questões trazidas pelas definições anteriores:

Sujet Parlant: [individuo che parla una lingua e produce atti di parole, ha coscienza dei soli stati di lingua in un momento dato, in questo senso costituisce il punto di riferimento della linguistica sincronica (Cfr. analyse)]; Le groupement des formes tel qu'il resulterait du passé, ce groupement est ignore completement du sujet parlant et force le grammairien à établir deux sphères distinctes (p. 67) Cfr. analyse1, conscience, grammairien, inconscient, instinct, intention, interne, linguistique, réservoir, sentiment, subconsciente, trésor, valeur, volonté $\{P h$; ED; Notes Item; LG; II corso; III corso $\}$. (COSENZA, 2016, p.485-466)

O falante é o "indivíduo que fala uma língua", tendo "consciência" do estado de língua no qual encontra-se imerso; esta posição de falante funciona como uma referência para a linguística sincrônica, conforme é possível verificar em diversos exemplos de Saussure, presentes de maneira reiterada nos Escritos de Linguística Geral (SAUSSURE, 2004 [2002]). Adiante retornaremos à discussão sobre falante e consciência a partir da leitura de Loïc Depecker (2012).

Quanto às notas do Segundo Curso (1908-1909), percebe-se que seguem na mesma direção da definição de sujet parlant, reforçando a relação do falante com a noção de sentimento e sublinhando o lugar destes conceitos no método proposto por Saussure, o qual é fundamentado no ponto de vista da sincronia:

Sujet parlant: [soggetto che parla una lingua. I soggetti parlanti costituiscono il punto di riferimento dela linguistica sincronica (Cfr. sentiment)]; Cette perspective du grammairien, du linguiste à pour étalon la perspective des sujets parlants, et il n'y a < pas d'autre méthode $>$ que de se demander quelle est l'impression des sujets parlants. Pour savoir dans quelle mesure une chose est, il faudra rechercher dans quelle mesure elle est dans la conscience des sujets parlants, [dans quelle mesure] elle signifie. $<$ Donc, une seule perspective, méthode: observer ce qui est ressenti par les sujets parlants.> (p. 49) Duale masse parlante; Cfr. analogie, casier, cerveau, conscience, création analogique, faculté du langage, formation analogique, individu,

\footnotetext{
${ }^{10}$ Em outro documento, o Notes Item (1899-1903), a definição reaparece: « Sujet parlant : [celui che parla una lingua]; Les sujets parlants n'ont aucune conscience des aposèmes qu'ils prononcent, pas plus que de l'idée pure d'autre part. Ils n'ont conscience que du sème. C'est là ce qui assure la transformation parfaitement mécanique de l'aposème à travers les siècles. (p. 109); Cfr. discours, discursif, langage, langue, langue discursive, parole, transmission, trésor. $\{P h ; E D ; L G$; I corso; II corso; III corso $\} »($ COSENZA, 2016, p.424).
} 
Volume 16 - Número 1 - jan/jul de 2021

langage/langue, magasin, novation analogique, sentiment, parole, volonté $\{\mathrm{Ph} ; \mathrm{ED}$; Notes Item; LG; I corso; III corso $\}$. (COSENZA, 2016, p.521)

Por fim, no Terceiro Curso (1910-1911), nota-se o acréscimo de uma referência à faculdade de linguagem relativa à aquisição de uma língua, ressaltando tanto a produção da parole quanto a consciência / percepção daquilo que é reconhecido como langue de um ponto de vista sincrônico:

Sujet parlant: [individuo dotato della faculté de langage che ha acquisito una langue e che produce atti di parole e ha coscienza della sola sincronia. In questo senso costituisce il punto di riferimento dela linguistica (statica o sincronica). Produce atti di parole con un certo grado di coscienza che hanno un ruolo primario nei cambiamenti linguistici anche se isolatamente presi non possono modificare la lingua]; En se plaçant au point de vue du sujet parlant: la suite des faits dans le temps est une chose inexistante. Le sujet parlant est devant un état. De même, le linguiste doit faire table rase $<$ de $>$ ce que est diachronique, de ce qui a produit un état dans le temps, pour comprendre cet état immense. Il ne peut entrer dans la conscience des sujets parlants qu'en adoptant le point de vue d'ignorance des sources. (p. 107) Duale masse parlante; cfr. abstraction, conscience, dépôt, faculté, individu, insctict, intelligence collective, langue, mécanisme1, parole, réalité, sensation psychique $\{P h ; E D$; Notes Item; LG; I corso; II corso $\}$. (COSENZA, 2016, p.561-2)

A partir desses recortes, pode-se dizer que o falante, nas considerações de Saussure, claramente aparece como um ponto de referência da linguística sincrônica; diríamos que se trata de uma testemunha, ainda que nem sempre consciente, da langue.

Quem se debruça sobre o falante e sua relação com a langue saussuriana é Loïc Depecker (2012) - o estudioso dedica o quarto capítulo de seu livro à "língua e a consciência dos sujeitos falantes". Apesar de sua atenção voltar-se particularmente à presença da consciência nos manuscritos de Saussure, as considerações de Depecker aproximam-se do sentimento linguístico que buscamos compreender. A noção de consciência, segundo o autor, aproxima o linguista do falante: "Para se guiar, o linguista tem, no sujeito falante, um correspondente da consciência: o sentimento que o sujeito falante se faz ou se poderia fazer da língua" (DEPECKER, 2012, p.110).

A visada do ponto de vista sincrônico como aquele que tem como referência o falanteobservação que ressoa em outros pesquisadores, conforme apontaremos a seguir - é crucial para atribuir ao falante um papel capital para a linguística de base saussuriana. Destacamos a observação de Depecker:

Para Saussure, o papel da consciência na língua não é um simples postulado. É um princípio fundamental. Pois como reconhecer um signo se a consciência não está implicada nessa ação? Pouco a pouco, a análise se aprofunda, dando lugar não apenas ao "espírito", à "consciência", mas ao "sujeito falante", que surge nos manuscritos dos anos 1894-1895. (DEPECKER, 2012, p.112-3)

É preciso que se observe que a noção de consciência (do falante, da langue) aqui mobilizada sinaliza uma aproximação com a ideia de percepção que o falante tem do fato de que, ao mobilizar formas simbólicas, produz efeito sobre outros falantes. Prova disso é que a langue é definida como aquilo que é compartilhado pelos falantes de uma dada comunidade linguística.

Para Saussure, o linguista que analisa determinado estado de língua não poderia renunciar ao falante; “O recurso ao 'sentimento' (...) é uma das ferramentas do linguista. De fato, seu trabalho deve se guiar pelo sentimento do sujeito falante, caso contrário ele corre o 
risco de se perder em abstrações" (DEPECKER, 2012, p.117). A seguir, voltamos nosso olhar ao termo sentimento a fim de melhor explorar a relação do falante com a dupla conceitual langue e parole, afinal, “o 'sentimento da língua' não apenas abarca a maneira pela qual os sujeitos falantes percebem a língua, mas também é um princípio metodológico, o principal guia do linguista" (DEPECKER, 2012, p.118).

Obviamente, as considerações aqui não pretendem excluir o ponto de vista diacrônico, que, como sabemos hoje, não foi descartado ou menosprezado por Saussure, mas justamente ressaltar que o conceito de falante opera na linguística sincrônica - constatação importante do linguista suíço. A partir dessas passagens, já foi possível vislumbrar, ainda que de forma introdutória, a noção de sentimento, discussão a qual nos dedicamos com maior detalhamento a seguir.

\section{0 sentimento da langue (ou seja, do falante)}

Após nos voltarmos a algumas das definições de sujet parlant, vejamos como o termo sentiment está presente nos escritos saussurianos a partir das análises de Engler (1968) e de Cosenza (2016). Em uma exploração inicial, detectamos uma definição no precioso Léxique de Rudolf Engler: « sentiment du sujet parlant $\rightarrow$ concret, conscience, réalité » (ENGLER, 1968, p.45). Sentimento, como se pode ler, está associado diretamente com a noção de sujet parlant, que identifica aquilo que é concreto e que pressupõe uma consciência linguística (ou seja, uma percepção de valor), conforme salientamos com Depecker (2012); tal percepção indica aquilo que é real (o que existe $=$ é reconhecido) em uma dada língua. Vejamos, por exemplo, a ocorrência de concret no Léxique:

concret : a) récl, répondant au sentiment des sujets parlants $3353,3-4$, cf. 'le concret réel $[\ldots]=$ ce qui est ressenti, ce qui à son tour [égale] ce qui est significatif à un degré quelconque' 1737 ; 'dans la langue est concret tout ce qui est présent à la conscience du sujet parlant' $2195 \neq b$ ) délimité : 'concret, ici, signifie que l'idée a son unité dans le support sonore' $2195, \mathrm{cf} . \rightarrow$ élément concret $\neq$ matériel 1805. $\rightarrow$ abstraction, mot, sens, unité Godel 257. (ENGLER, 1968, p.17)

O objeto da linguística - a langue - é indissociável do sentimento dos falantes, pois é a partir do ponto de vista daqueles que falam (escrevem, escutam, leem...) que apreendemos, mesmo que efemeramente, aquilo que é real linguisticamente falando. A realidade da langue, nesse sentido, é possível apenas enquanto parole, pois é na cadeia falada (chaîne parlée) que os falantes operam a delimitação das unidades linguísticas. Acerca do que é real, lemos no Léxique:

réalité: a) 'fait présent à la conscience des sujets parlants' $2769(3293,14) \neq$ abstraction : 'Il est faux que les distinctions comme $\rightarrow$ racine, $\rightarrow$ thème, $\rightarrow$ suffixe soient des abstractions. Avant tout, et avant de venir parler d'abstraction, il faut avoir un critère fixe touchant ce qu'on peut appeler réel en morphologie. Criterium : ce qui est réel, c'est ce dont les sujets parlants ont conscience à un degré quelconque (....). (ENGLER, 1968, p.43)

Retornemos a Cosenza (2016) a fim de resgatarmos algumas das ocorrências de sentiment em sua coleção terminológica ${ }^{11}$. Em De la double essence du langage (1891-1892), Cosenza aponta uma aproximação entre as noções de sentimento e consciência:

\footnotetext{
${ }^{11}$ Confere nota 8.
} 
Sentiment: [hapax; v. conscience]; car a) le sens peut varier sans que le sentiment de l'unité du signe soit même vaguement atteint par ces variations (...) Cfr. conscience, esprit, état de langue, mental, opération, pensée, psychique, sujet parlant. \{LG; I corso; II corso . (COSENZA, 2016, p.358)

Nas lendas germânicas (1903-1910), vemos, guiadas por Cosenza, que o termo aparece como o saber próprio de uma comunidade, refletindo acerca da transmissão dessas lendas ao longo do tempo:

Sentiment: [il sentire, il sapere condiviso proprio di una comunità. In particolare S. discute il suo ruolo nella costituzione e trasmissione di una leggende]; (...) Cfr. état de langue, état de légende, fixe, langue, légende, massa sociale, mot, sémiologie, signe vocal, sujet parlant, symbole, transmission, unité, valeur, volonté. \{ED; I corso; II corso $\}$. (COSENZA, 2016, p.444)

Quanto às notas do Primeiro Curso (1907), vemos claramente a associação entre sentimento e o ponto de vista sincrônico, dependente dos falantes:

Sentiment: a) [il sentire cosciente, subcosciente o incosciente dei soggetti parlanti rispetto alle unità della lingua, tale sentimento si riferisce solo alla langue nel senso sincronico e costituisce il punto di riferimento di tale ambito di studio]; La régularité $<$ de structure quelle qu'elle soit $>$ aide les sujets parlants $<$ à reconnaître l'unité radicale en développant chez eux un certain sentiment linguistique. $>$ (p. 79) b) [il sentire della langue in quanto entità sociale posseduta dai soggetti parlanti (Cfr. langue)]; (...). $<$ Ainsi $>$ la langue peut avoir le sentiment de l'existence de ces préfixes à un degré très divers, $<$ et c'est dans la mesure de ce sentiment qu'>ils sont une réalité pour la langue. (p. 73) cfr. conscience, inconscient, subconsciente; instict, intention, intérieur, interne, langue, sujet parlant, volonté $\{\mathrm{ED}$; LG; II corso\}. (COSENZA, 2016, p.483)

Além disso, Cosenza lança mão da expressão "o sentir da langue”, tomada "enquanto entidade social possuída por falantes", observação respaldada pela exaustiva amostra que o autor realiza. Na passagem acima, a langue, personificação daqueles que falam, pode ter/proporcionar o sentimento da existência de uma unidade linguística.

Nas anotações referentes ao Segundo Curso (1908-1909), sentimento é associado a um conhecimento "prático"/empírico do falante, que geralmente é implícito. Tal saber serve de critério para a análise linguística:

Sentiment: [conoscenza pratica, in genere non esplicita, che il soggetto parlante ha della propria lingua e che si mostra negli atti linguistici, punto di riferimento della linguistica sincronica in quanto determina la langue. In questo senso è da intendersi socialmente dei soggetti parlanti]; (...) Ce qui est significatif se traduit par une délimitation d'unité, c'est la signification qui la crée, elle n'existe pas avant: $<$ ce ne sont pas les unités qui sont là pour recevoir une signification.> (p. 24) Cfr. conscience, langage/langue, langue, parole, sujet parlant, volonté $\{\mathrm{ED}$; LG; I corso $\}$. (COSENZA, 2016, p.519)

Conforme a passagem acima, o sentimento delimita aquilo que é significativo em termos de langue. Eis o ponto de partida que une o "sentimento do falante" à tarefa (ou método) do linguista. 
Apesar da ampla presença de sentimento nos manuscritos saussurianos, são escassos os trabalhos encontrados que lidam especificamente com uma problematização acerca do termo. Para além de Loïc Depecker (2012), cujo debate abordou a consciência dos falantes, Alessandro Chidichimo (2009) e Emanuele Fadda (2013) são dois pesquisadores que se debruçam sobre a questão. Vejamos como esses estudiosos contribuem para a reflexão acerca do sentimento enquanto termo linguístico.

Em "Saussure e o Sentimento: A forma do Sentimento Linguístico", Alessandro Chidichimo (2009) lança aos leitores dois questionamentos: primeiro interroga "[p]or que os falantes sentem que as palavras que eles utilizam para falar são adequadas para aquilo que eles dizem?"; em seguida, pergunta sobre "[o]nde está pautada sua certeza?" (CHIDICHIMO, 2009, p.109). A nós, interessa sublinhar aqui que o sentimento, para Chidichimo, ancora-se no falante, visto que é a partir da parole que acessamos concretamente a langue. Vale ressaltar também que, conforme observado pelo autor, sentimento pode ser tomado em Saussure como termo ou como palavra de uso comum. Apesar de nem sempre figurar em seu valor epistemológico, "a maior parte do tempo parece explicar a dinâmica do sujeito falante individual com a língua, que permanece sempre coletiva, mas que é submissa às mudanças introduzidas pela fala, que é ao contrário sempre individual" (CHIDICHIMO, 2009, p.110-111). Os recortes e definições operados por Giuseppe Cosenza (2016) acerca do termo sentimento, conforme apontado acima, parecem estar de acordo com a perspectiva de Chidichimo, para quem "[o] ponto de encontro entre o sujeito e a língua em relação ao sentimento se verifica quando Saussure fala da realidade da língua" (CHIDICHIMO, 2009, p.113, grifos do autor).

Emanuele Fadda é outro pesquisador que investiga a fundo a questão do sentimento a partir de Saussure, visto como "seule base possible pour tout classement linguistique" (FADDA, 2013, p.49). Fadda, no artigo "'Sentiment': entre mot et terme. Quelques notes sur le travail et la langue de Ferdinand de Saussure" (FADDA, 2013), problematiza o uso da expressão sentiment no corpus saussuriano, buscando investigar seu sentido epistemológico. Em interlocução com o artigo de Chidichimo (2009), Fadda alarga a noção de sentimento a fim de pensar o termo para além de sua relação com a posição do falante como indivíduo. O ponto crucial abordado por Fadda é que sentimento não estaria atrelado essencialmente à sincronia (nem à diacronia), mas à morfologia. A tese do estudioso é a seguinte:

le sentiment, chez Saussure, c'est en terme le moyen (pour le sujet parlant) et le critère (pour le linguiste) de toute analyse morphologique. En tant que tel, il fonde et définit la morphologie, et en est le véritable objet. (FADDA, 2013, p.54)

Ou seja, o sentimento é o meio que o falante possui para a análise morfológica; quanto ao linguista, o sentimento nada mais é que seu próprio critério de análise.

Fadda fundamenta sua reflexão nas notas do curso de gramática comparada greco-latina ministrado por Saussure entre 1909 e $1910^{12}$; a partir da leitura do material, o pesquisador destaca quatro pontos importantes para a discussão acerca do sentimento tendo como base a morfologia ${ }^{13}$ :

(1) a morfologia é responsável pelo "recorte" das unidades linguísticas;

\footnotetext{
${ }^{12} \mathrm{O}$ pesquisador sublinha que o material é pouco trabalhado entre os estudiosos do corpus saussuriano: « Le cours de grammaire comparée gréco-latine de 1909-1910 est divisé en deux parties, de longueurs inégales: phonétique (bien plus longue) et morphologie. (...) Les notes sur la morphologie - dans la version de Riedlinger - ont été employées dans la rédaction du $C L G$, et ont été mentionnées par Godel et Engler, mais elle n'ont pas été publiées jusqu'à présent (du moins pas intégralement) » (FADDA, 2013, p.54-55).

${ }^{13} \mathrm{O}$ termo morfologia faz referência ao estudo das formas em geral, e não à morfologia como um dos níveis de análise linguística, tal como se concebe atualmente no terreno da linguística.
} 
(2) o critério para que o "recorte" seja delimitado é a coincidência com aquilo que é feito pelos falantes da língua em questão;

(3) tal "recorte" é operado com base no sentimento desses falantes;

(4) o sentimento pode ser entendido como uma espécie de "conscience faible", "instinct" (FADDA, 2013, p.56).

A partir daí, como podemos pensar o sentimento? Podemos sintetizá-lo em um reconhecimento da unidade - ou seja, do signo.

A tradução dos Escritos de Linguística Geral foi responsável por trazer em primeira mão algumas dessas reflexões para a língua portuguesa. Em uma das passagens pertencentes aos antigos documentos de Engler, originalmente intitulada Morfologia (cf. SAUSSURE, 2004 [2002], p. 155), encontramos passagens interessantes as quais retomam as definições encontradas tanto no Léxique de Engler (1968) quanto em Cosenza (2016): "Não esqueçamos que tudo o que existe no sentimento dos sujeitos falantes é fenômeno real" (SAUSSURE, 2004 [2002], p.160, grifo nosso); "no nono século, verdade é o que sentem os alemães do nono século, absolutamente mais nada" (SAUSSURE, 2004 [2002], p.160, grifo nosso); quanto ao valor de unidades morfológicas, especificamente do prefixo en-, Saussure sublinha: "no francês de nossos dias, enfant, entier não comportam, no sentimento dos franceses, nenhuma espécie de análise, não mais do que comportaria a palavra pour ou a palavra moi" (SAUSSURE, 2004, p.161, grifo nosso). Na mesma direção do sentimento dos falantes, encontramos o sentimento da langue:

Se digo que chanteur, no século XIX, se decompõe em chant + eur, eu estou de acordo com o sentimento da língua, que se traduz por formações novas e, se eu dissesse que ela se decompõe em chan = teur, minha análise não corresponderia a nada. (SAUSSURE, 2004 [2002], p.166, grifo nosso)

Se a langue é o objeto da linguística, em companhia de Fadda, podemos afirmar que o sentimento é o objeto da morfologia, tendo em vista que o sentimento orienta a delimitação das unidades linguísticas:

le sentiment est l'objet de la morphologie, tout comme la langue est l'objet de la linguistique, exactement dans le sens éclairé par De Mauro: ce n'est pas la chose sur laquelle il faut travailler, mais plutôt le résultat, le $\tau \dot{\varepsilon} \lambda o \varsigma$ de l'activité du morphologiste, ce qu'il va obtenir à la fin de son travail. Si l'objet de la linguistique est la langue, l'objet de la morphologie est le sentiment des sujets parlants qui les guide dans leurs analyses morphologiques. (FADDA, 2013, p.57)

Para além da associação entre sentimento e morfologia, Emanuele Fadda estabelece um paralelo com a relação dos termos sensação e fonética. Essa perspectiva reforça o que temos apontado em alguns trabalhos voltados ao papel do ouvido (oreille) na reflexão linguística saussuriana, que opera como metonímia do falante. No CLG, lemos, por exemplo, que "é na cadeia da fala ouvida que se pode perceber imediatamente se um som permanece ou não igual a si próprio; enquanto se tenha a impressão de um som homogêneo, este som é único" (SAUSSURE, 1974 [1916], p.50). A impressão ou sensação de unidade está atrelada ao fenômeno físico (seja através de uma materialidade sonora ou visual), mas não se limita a um reconhecimento de ordem fisiológica. Como bem observa Fadda,

Une lecture même hâtive de ce texte montre que l'élément central des opérations dont il est question en phonétique (et que le phonéticien doit reconstruire - tout comme le morphologiste reconstruit les analyses dictées par le sentiment du sujet parlant), est bien l'oreille. Saussure emploie 
toujours ce mot (absent, lui aussi, des lexiques de Godel et d'Engler) pour désigner l'agent de ces opérations. (FADDA, 2013, p.57, grifos nossos)

O "morfologista" necessita ir em busca do sentimento do falante; o "foneticista" (e/ou o fonólogo, acrescentamos) depende da sensação percebida pelo ouvido. Fadda, nessa direção, situa sentimento e sensação como os meios através dos quais as unidades linguísticas são construídas, equiparando, poderíamos dizer, falante e ouvinte na medida em que

L'oreille est souveraine dans sa sphère de compétence : elle juge (cf. PH., II, $4 \mathrm{v}, 17 \mathrm{r}$; III, 6v) et même décide (PH III, 10r) - et ses jugements seront loi contraignante pour le linguiste ; contraignants pour son travail ; mais elle ne ressent rien (du moins, dans l'acte de parole). Elle saisit, plutôt, selon le mot de Parret (1995-6 : 100 ssq), qui l'appelle « la 'faculté' en nous qui saisit le physicoacoustique et sa temporalité » (ibid.: 105). (FADDA, 2013, p.58)

Apesar de aproximar falante e ouvido, sentimento e sensação, Fadda compreende que há uma diferença importante de salientar: enquanto podemos individualizar a sensação reconhecida pelo ouvido, o sentimento do falante não diz respeito apenas a uma percepção individual, mas social, da ordem do coletivo. Essa interpretação faz sentido, na medida em que em mais de uma ocorrência o termo sentimento vem acompanhado de falantes no plural (falantes de alemão, francês etc.) ou mesmo do termo langue. O que podemos depreender do debate acerca do sentimento é que, de fato, tal termo parece enfatizar o caráter indissociável entre langue e parole, visto que a langue é definida e delimitada a partir daqueles que falam e escutam.

\section{Considerações finais}

Iniciamos este artigo buscando compreender as implicações do termo falante (sujet parlant) para a reflexão linguística de base saussuriana. O levantamento das definições selecionadas em Cosenza (2016) permitiu-nos vislumbrar o entrelaçamento entre o falante não apenas identificado como aquele que fala; para além da constatação de indivíduo falante de determinada língua, o falante opera como alicerce do ponto de vista sincrônico e, portanto, é um meio para a análise linguística. Nesse sentido, este é um princípio basilar para o estudo da langue; ao falante, estão atreladas as noções de consciência e sentimento. Aqui, buscamos explorar a definição de sentimento em decorrência do papel que tal concepção parece desempenhar na delimitação do signo linguístico.

O sentimento, como procuramos analisar até aqui, está atrelado às noções de concretude e realidade da langue: ambas reforçam o laço entre langue e parole, na medida que não é possível abstrairmos o sistema linguístico relegando aqueles que falam a um simples fator externo. Quando abordamos o sentimento do(s) falante(s) ou da langue estabelecemos um laço entre empiria e teoria; entre parole e langue. Cremos que o sentimento, tomado em seu sentido especializado, pode ser encarado como um princípio epistemológico: tal princípio fundamenta o recorte das unidades linguísticas na cadeia falada (chaîne parlée). Nesse sentido, o rastro do aspecto fônico da langue parece ser uma instigante pista do sentimento que o(s) falante(s) partilham, ao compartilharem formas e sentidos.

Ainda cabe aprofundar a questão terminológica com apoio em pesquisas específicas sobre o léxico saussuriano e para além deste, visto que falante, apesar de ser um termo recorrente, carece muitas vezes de uma definição clara; já sentimento não é um termo sobre o qual linguistas se debruçam cotidianamente. Mesmo com uma amostra ainda restrita, acreditamos ser possível antever hipótese de uma relação do termo sentimento com a posição de análise linguística, encarnada pelo(s) falante(s), pelo ouvido ou pela própria langue. A 
análise linguística, dessa perspectiva, parece demandar um lugar de alteridade, considerando aquilo que é sentido, ouvido e delimitado sob efeito da escuta da cadeia discursiva.

\section{Referências}

CASTRO, M. F. P. “Sobre a analogia na reflexão saussuriana”. In: DELTA - Documentação de Estudos em Linguística Teórica e Aplicada, São Paulo, v. 34, n. 3, p. 815-834, jul./set. 2018. Disponível em: https://www.scielo.br/pdf/delta/v34n3/1678-460X-delta-34-03815.pdf. Acesso em: 23 mar. 2021.

CHIDICHIMO, A. "Saussure e o sentimento: a forma do sentimento linguístico". In: RUA, Campinas, SP, v. 15, n. 1, p. 109-122, 2015. DOI: 10.20396/rua.v15i1.8638875. Disponível em: https://periodicos.sbu.unicamp.br/ojs/index.php/rua/article/view/8638875. Acesso em: 20 mar. 2021.

COSENZA, G. Dalle parole ai termini: i percorsi di pensiero di F. de Saussure. Alessandria: Edizioni dell'Orso, 2016.

DEPECKER, L. Compreender Saussure a partir dos manuscritos. Trad. Maria Ferreira. Petrópolis, RJ: Vozes, 2012.

ENGLER, R. Léxique de la terminologie saussurienne. Utrecht-Anvers, Spectrum, 1968. FADDA, E. « 'Sentiment' entre mot et terme. Quelques notes sur la langue et le travail de Ferdinand de Saussure », In: Cahiers Ferdinad de Saussure, n. 66, 2013, p. 49-65. Disponível em: http://www.jstor.org/stable/24324189 Acesso em: 20 mar. 2021. MILANO, L. " Le statut du phonique dans le 'CLG' ». In: Cahiers Ferdinand De Saussure, n. 70, 2017, p. 85-100. Disponível em: https://www.jstor.org/stable/45212071 Acesso em: 21 mar. 2021.

MILANO, L; STAWINSKI, A. "O arbitrário e/é a escuta". In: Todas as Letras - Revista de Língua e Literatura, São Paulo, v. 22, n. 2, p. 1-17, maio/ago. 2020. Disponível em:

http://editorarevistas.mackenzie.br/index.php/tl/article/view/13398 Acesso em: 20 mar. 2021. RIBEIRO, J. "A língua é um traje coberto de remendos feitos de seu próprio tecido": uma reflexão sobre os neologismos a partir da teoria saussuriana. Dissertação de mestrado. Universidade Federal do Rio Grande do Sul, Instituto de Letras. Programa de Pós-Graduação em Estudos da Linguagem, 2019. Disponível em: http://hdl.handle.net/10183/202470 Acesso em: 20 mar. 2021.

SAUSSURE, F. de. Curso de linguística geral. Organização por Charles Bally e Albert Sechehaye; colaboração de Albert Riedlinger. Tradução de Antônio Chelini, José Paulo Paes e Izidoro Blikstein. São Paulo: Cultrix, 1974.

SAUSSURE, F. de. Phonétique. Il manoscritto di Harvard. Houghton Library, edizione a cura de Maria Pia Marchese, Università degli studi di Firenze. Padoue : Unipress, 1995.

SAUSSURE, F. de. Escritos de Linguística Geral. (org.: Simon Bouquet e Rudolf Engler). São Paulo: Cultrix, 2004 [2002].

SILVA, K. A. "A analogia e o sentimento do sujeito falante em Saussure". In: DELTA Documentação de Estudos em Linguística Teórica e Aplicada, São Paulo, v. 34, n. 3, p. 919940, jul./set. 2018. Disponível em: https://www.scielo.br/pdf/delta/v34n3/1678-460X-delta34-03-919.pdf. Acesso em: 23 mar. 2021.

SOFIA, E. O estudo da obra de Ferdinand de Saussure: problemas teóricos, filológicos e editoriais. $123^{\circ}$ Seminário de Estudos Avançados. UFSM, Silveira Martins, 2019.

(Comunicação Oral). 
Volume 16 - Número 1 - jan/jul de 2021

STAWINSKI, A.; MILANO, L. Sobre objeto e método: do CLG ao manuscrito Phonétique. In: Gragoatá, Niterói, v.22, n. 44, p. 1172-1183, set.-dez. 2017. Disponível em:

https://periodicos.uff.br/gragoata/article/view/33554 Acesso em: 21 mar. 2021.

Submetido em 23/03/2021

Aceito em 20/08/2021 